\title{
Percutaneous Endoscopic Removal of Extruded Centering Pin in Lumbar Artificial Disc Causing Postoperative Radiculopathy: A Case Report
}

\author{
Chul-Woo Lee, Kang-Jun Yoon, Sang-Soo Ha \\ Department of Neurosurgery, St. Peter's Hospital, Seoul, Korea
}

Corresponding Author:

Chul-Woo Lee, MD, PhD

Department of Neurosurgery, St. Peter's Hospital, 2633,

Nambusunhwan-ro, Gangnam-gu, Seoul 06268, Korea

Tel: $+82-1544-7522$

Fax: +82-2-574-9414

E-mail: mannitol240@gmail.com

Received: December 29, 2017

Revised: January 21, 2018

Accepted: March 6, 2018
We present a case of postoperative radiculopathy caused by extrusion of centering pin marker in lumbar artificial disc treated by percutaneous endoscopic procedure. A 39-year-old man was presented with intermittent electric shock like left leg pain along S1 dermatome. He received lumbar total disc replacement (TDR) on L5-S1 for his degenerative disc disease (DDD) six years before the revisit to the clinic. X-ray and CT revealed extruded pin from the core of the implant compressing the thecal sac and left S1 root. The position and mobility of the implant were seen intact in follow-up X-rays. The marker pin was removed by percutaneous endoscopic interlaminar technique. The patient's preoperative leg pain was completely resolved after the procedure.

Key Words: Lumbar arthroplasty, Implant failure, Percutaneous lumbar endoscope

\section{INTRODUCTION}

One of concerns in artificial lumbar disc is long-term durability. There have been a few reports about implant-related undesirable complications in lumbar artificial disc such as subsidence, dislocation of implant, wear debris, and polyethylene core rim fracture ${ }^{1,3,11,12,16,20)}$. Several kinds of salvage procedures for implant failure in lumbar total disc replacement (TDR) have been introduced, including posterior stabilization, re-insertion of implant or removal of implant, and fusion surgery with anterior revision ${ }^{6,13,15,17)}$. We present a case of postoperative radiculopathy caused by extrusion of centering pin marker in lumbar artificial disc treated by percutaneous endoscopic procedure.

\section{CASE REPORT}

In 2006, an active 39-year-old man was presented with progressive intractable back pain caused by degenerative disc disease (DDD) at L5- S1 with normal facet joints (indicative of TDR) confirmed by diagnostic radiological studies (provocative discography) (Fig. 1). Non-operative management failed. Therefore, he subsequently underwent TDR at L5-S1 with artificial disc (Mobidisc ${ }^{\circledR}$; LDR Médical, Troyes, France). Uncoated prosthesis endplates were size T8, medium, with $5^{\circ}$ lordotic angle. The height of the polyethylene core was $10 \mathrm{~mm}$. A standard right-sided anterior retroperitoneal approach was performed. A window annulotomy technique ${ }^{7)}$, including suturing of the anterior longitudinal ligament (ALL) and annulus, was used following implantation of the prosthesis. The patient tolerated the surgery
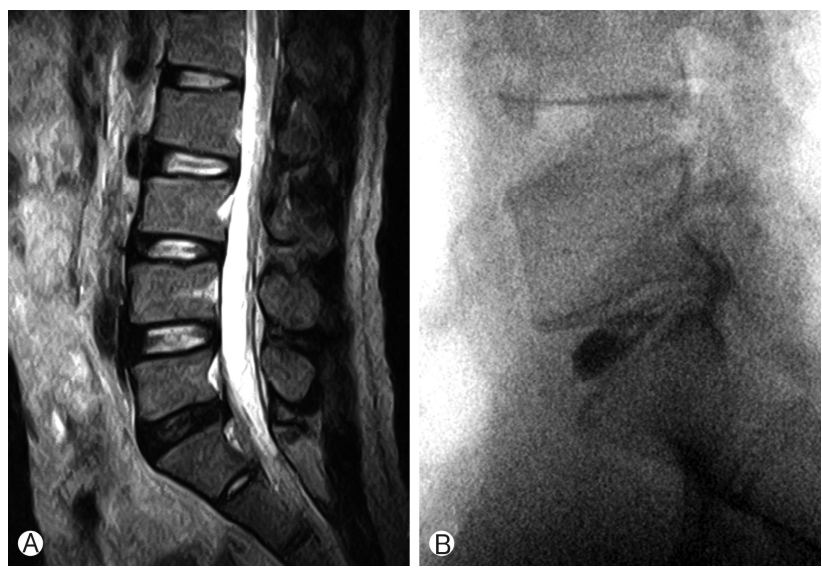

Fig. 1. Preoperative images. (A) Preoperative T2-weighted magnetic resonance image of the lumbar spine in sagittal view. (B) Preoperative discography revealing a painful disc degeneration at L5-S1. 

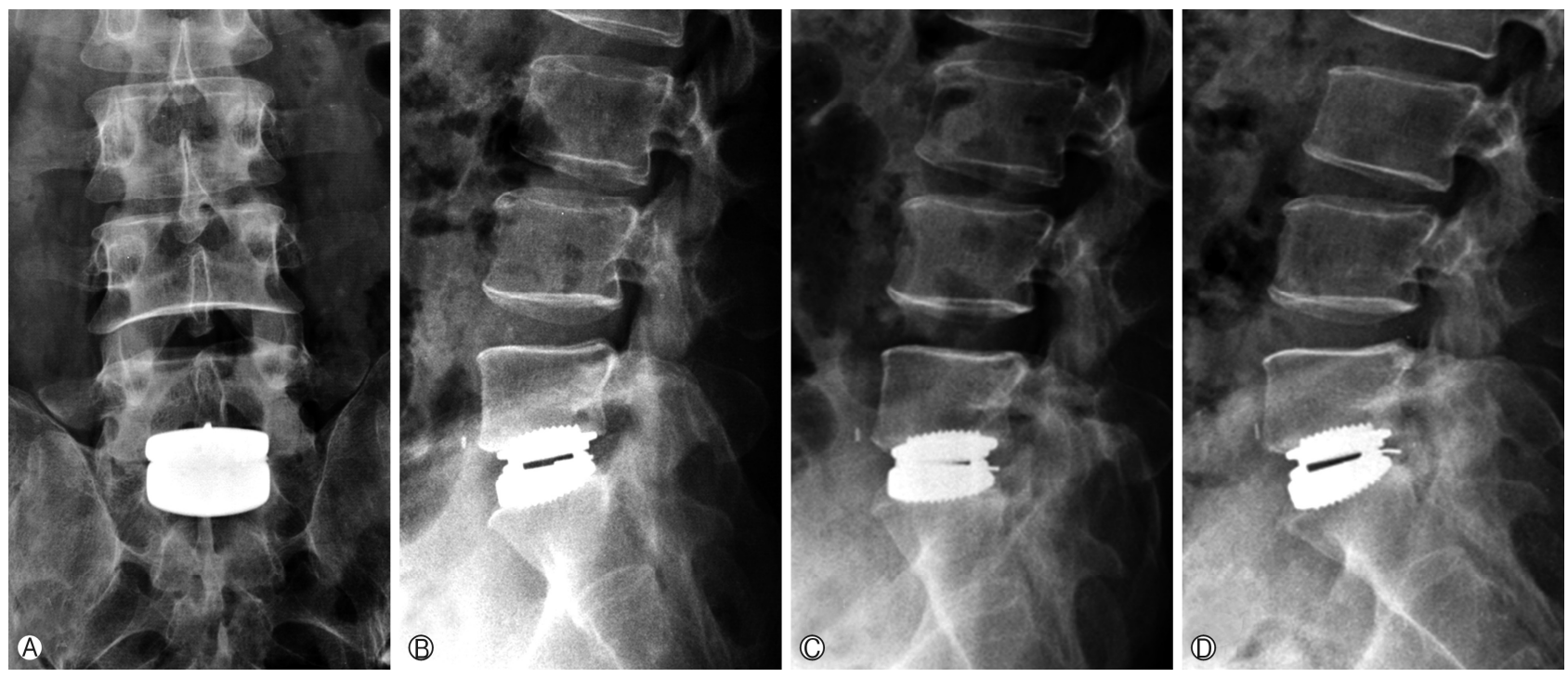

Fig. 2. Follow-up of postoperative simple X-rays. (A) Immediate postoperative X-ray, AP view. (B) Immediate postoperative X-ray, Lateral view. (C) Postoperative $X$-ray one year after the initial operation, Lateral view. (D) Postoperative $X$-ray at four years after the initial operation, Lateral view.

well. He encountered no early postoperative complications. Immediate postoperative radiographs confirmed ideal placement of implant (Fig. 2A, 2B). Radiographic evaluation that was conducted one year after the initial surgery showed an intact implant with slight posterior migration of centering pin from its original position (Fig. 2C). More posterior migration of the pin was observed in follow-up $x$-ray which was taken four years after the surgery (Fig. 2D). However, the patient was pain-free. He was able to perform all his prior daily activities since he returned to work from the initial surgery. The patient remained pain-free with an excellent functional and clinical results until 6.5 years after the surgery. At that time, the patient was presented with intermittent moderate low-back pain. In 2012, the patient revisited our clinic with left leg pain which occurred one week ago. The pattern of leg pain was intermittent, electric shock like, and position dependent. The pain was aggravated by position change such as standing and bending motion. Plain lateral flexion and extension radiographs demonstrated intact position and mobility of the implant. More extruded pin from the core was revealed. CT scans confirmed posterior migration of the pin marker into the spinal canal from the core in artificial disc (Fig. 3), suggesting that it might be compressing thecal sac and S1 nerve root. We didn't perform the diagnostic block before the second operation because radiologic study didn't show other pathology except extruded centering pin in L5-S1, which was compatible with newly developed patient's left leg pain (S1 dermatome). Rescue procedure was performed via a percutaneous endoscopic interlaminar approach to remove the extruded pin. The intervention was made for the patient at prone position under epidural anesthesia and radiological control. $7 \mathrm{~mm}$ skin incision was made nearly medial in the craniocaudal middle of the interlaminar window. A dilator ( $6 \mathrm{~mm}$ in outer diameter) was inserted bluntly to the lateral edge of the interlaminar
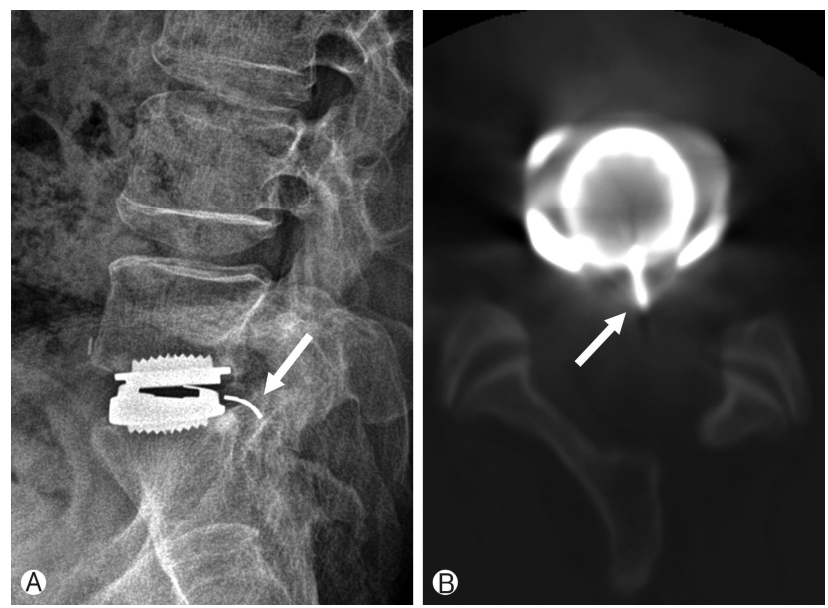

Fig. 3. Extruded wire marker pin from the core. (A) Postoperative $\mathrm{X}$-ray at six years after the initial operation, Lateral view. (B) Postoperative CT at six years after the initial operation, axial view. Arrow: Extruded marker pin from the core into spinal canal.
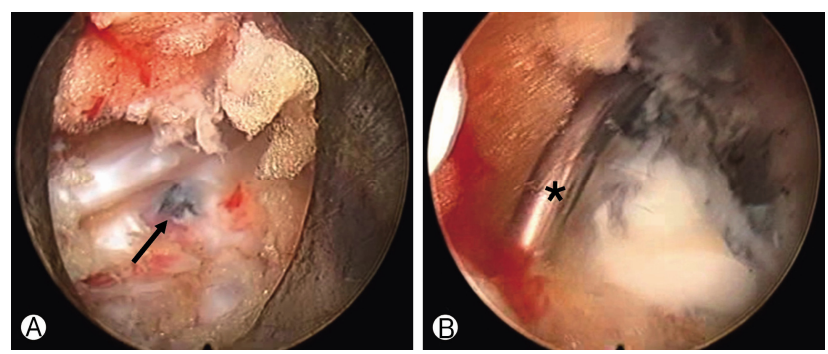

Fig. 4. Intraoperative endoscopic finding. (A) Arrow: Greyish discoloration in annulus and PLL. (B) Asterisk: Extruded tip of wire marker pin. 
window. Then an operation sheath with $7 \mathrm{~mm}$ outer diameter and beveled opening was directed toward the ligamentum flavum. Further procedure was performed under endoscopic visual control and constant irrigation. A lateral incision was made in the ligamentum flavum which was extended to about $5 \mathrm{~mm}$ (ligamentum flavum splitting technique) ${ }^{8)}$. Neural structures were exposed while preserving the epidural lubricating fat tissue. During the procedure, protruded posterior longitudinal ligament (PLL) and a part of annulus were seen. Tip of the pin was observed to be covered with greyish discolored PLL and annulus (Fig. 4A). Some dissection around the protruded area by radiofrequency (RF) bipolar revealed the tip of the extruded pin (Fig. 4B). Adhesion around the protruded areas was not severe. Extruded pin from disc space was removed easily by endoscopic forcep. Adhesiolysis between the point where the pin was removed and near the neural structure was performed. The patient's symptom dramatically improved immediately after the procedure. No complications such as postoperative dysthesia, dura tear, or hematoma occurred. The patient was discharged one day after the surgery.

\section{DISCUSSION}

The use of intervertebral disc prostheses as an alternative to spinal fusion has been advocated to preserve segmental motion and prevent adjacent segment disease. However, lumbar arthroplasty has also received some skepticism and concern. The issue of arthroplasty failure and potential complications associated with adhesions at revision surgery have highlighted potential pitfalls in the application of this new technology, 3,15,21). Failure in lumbar TDR has been reported with symptoms of unbearable back pain and radiculopathy in various clinical manifestations such as device migration, subsidence, facet arthrop- athy, and wear from metallic implant endplates or polyethylene core $^{1,12,18-20)}$. Several previous articles have shown various surgical methods to deal with TDR failure ${ }^{13,17,21)}$. The present case was unique in that postoperative radiculopathy in lumbar TDR was caused by only extruded centering pin marker with radiologically intact shape and position of other components in artificial disc. It was resolved by percutaneous endoscopic technique in the most simple and minimal invasive way. To the authors' knowledge, this is the first report showing that the complication from implant failure in lumbar TDR was figured out by percutaneous endoscopic technique.

Failure of disc arthroplasty can be due to any number of factors. Suboptimal surgical technique, improper sizing and/or positioning of the implants, and poor patient selection account for the majority of lumbar disc failures $1,3,9,13,17$. Malposition of mis-sized implant is considered as the most common cause of implant failure. Isolated device-related complications (e.g., subsidence, body fractures, polyethylene extrusion, and problems due to polyethylene wear) are rare. In the present case, radiographic evaluation revealed an appropriately sized and properly placed disc prosthesis. We observed coverage of $82.7 \%$ of the endplate on the lateral radiograph and $67.1 \%$ coverage on the anteroposterior radiograph. The extrusion of marker pin might be due to chronic rim impingement during normal flexion- extension or lateral flexion movements as reported in previous studies $^{10,14,16,18)}$. Regardless of excellent surgical technique and precise insertion of the prosthesis, the extrusion of the centering pin marker, a component in TDR implant, might imply the lack of durability in TDR.

A number of revision strategies have been used to treat "failed" disc arthroplasty. With an acceptable implant position, posterior lumbar stabilization can be used to address persistent back pain originated from facet joint or pain associated with
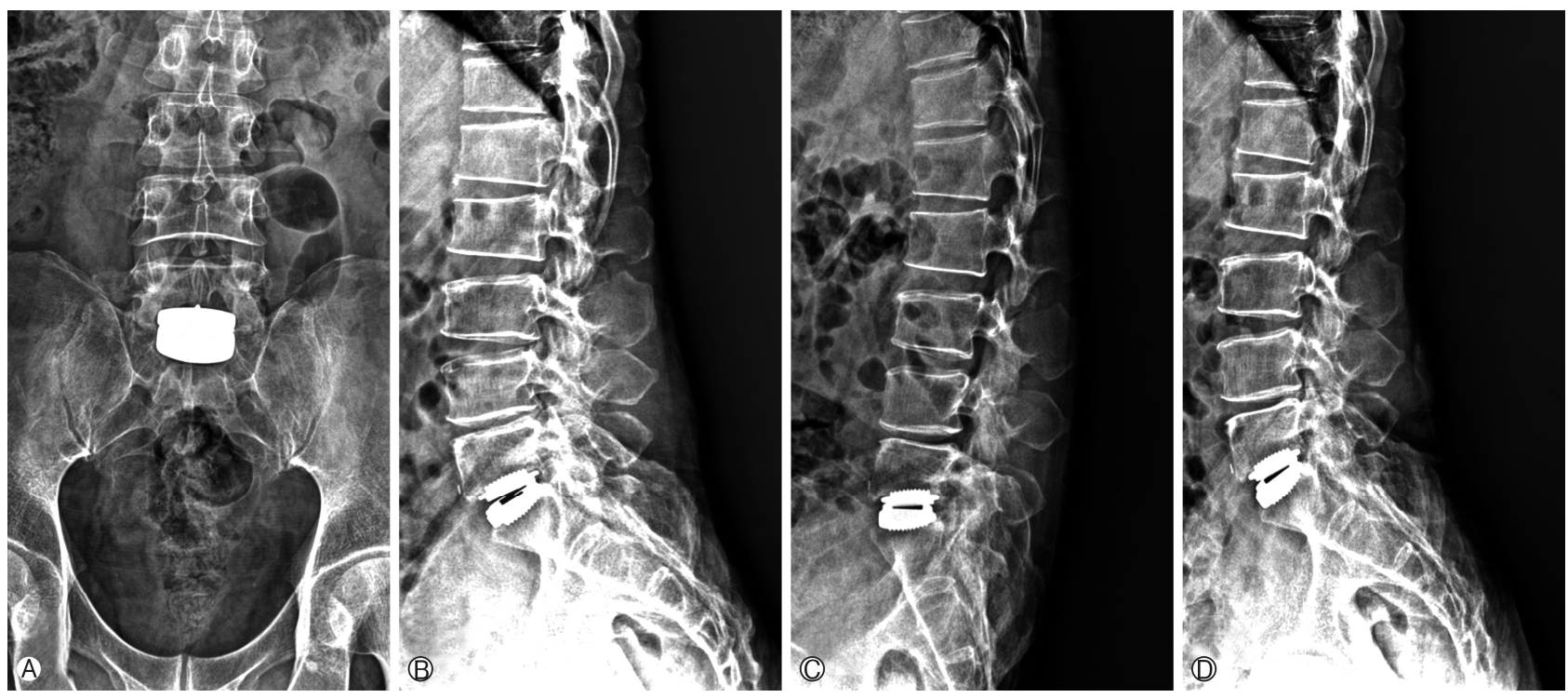

Fig. 5. Postoperative simple X-rays at 11 years after the initial operation. (A) AP view. (B) Lateral view. (C) Flexion view. (D) Extension view. 
instability of the lumbar prosthesis. Posterior stabilization may be achieved through either instrumented posterolateral fusion or posterior dynamic stabilization ${ }^{13,15,19)}$. Situations in which the arthroplasty device has migrated, subsided, or mechanically failed may be addressed with a posterior procedure or through either a revision of the arthroplasty or a conversion to an anterior arthrodesis. Either of the two latter options mandates a revision anterior approach to access the arthroplasty device ${ }^{6,11,19)}$. The revision approach, either retro or transperitoneal, is associated with significant risk to great vessels as well as other visceral structures due to adhesions and fibrosis from the original surgical exposure ${ }^{3,4,6,15)}$. Additionally, new surgical exposures such as the transpsoas or "far lateral" approach can bypass at risk structures and offer access to the anterior spinal column at L4-L5 and above $e^{11,15,19)}$.

However, in the present case, a grave anterior revision or posterior stabilization surgery was not necessary because only extruded pin marker was the cause of the postoperative radiculopathy. Therefore, we tried to seek the most minimally invasive method to remove the pin which compressed the neural structure without any manipulation of the implant or around segmental structures. Endoscopic operations have become standard in various areas such as arthroscopy and laparoscopy. Herniated discs and stenosis of the lumbar and cervical spine can now also be operated fully endoscopically using various accesses and techniques ${ }^{2,5,9,10,14)}$. We chose the percutaneous endoscopic technique as the rescue procedure to remove the extruded wire marker in this case. During the procedure, we were able to remove the extruded pin with minimized muscle and soft tissue injury and without any injury to the facet joint. The extruded marker pin covered by PLL was easily explored and successfully removed by simple endoscopic instruments such as a dissector and a forcep. Favorable clinical outcome was acquired with minimal injury and manipulation on the index segment by secondary percutaneous endoscopic procedure. Some discoloration of PLL suspicious of metallosis of the periprosthetic tissue probably due to impingement of the broken marker pin from the core was observed in direct endoscopic view during the procedure. Although further investigation for intradiscal wear debris by annulotomy was not performed, such an operative finding in detail could be missed in microscopic operation or in surgery with gross eyes. Such a detailed operative finding would be one advantage that surgeons can experience in endoscopic spine surgery.

Wire marker migration or breakage is not a benign radiographic observation in TDR, but a clinical predictor of damage to the polyethylene core. Therefore, previous studies have strongly recommended routine follow-up for patients with evidence of radiographic wire marker breakage ${ }^{12,16)}$. Fortunately, x-rays for the present case taken at the last follow-up (12 years after the initial operation) also revealed intact status of implant without subsidence or migration (Fig. 5) and the patient showed favorable clinical outcome. Although there was an implant failure like extrusion of centering pin, this case showed the longevity of lumbar TDR. Such minimally invasive surgical technique like percutaneous endoscopic procedure could provide minimal violation of segmental stability, and this might have contributed to the favorable long-term clinical outcome and maintenance of the artificial disc implant in this case.

\section{CONCLUSION}

Spinal surgeon should keep in mind that implant failure in TDR can be one of the causes of postoperative radiculopathy. Percutaneous endoscopic lumbar procedure can be used as one surgical option to treat failure in lumbar TDR in a minimally invasive way.

\section{REFERENCES}

1. A van $\mathrm{O}, \mathrm{AJ}$ V: Complications of artificial disc replacement: A report of 27 patients with the SB Charite disc. J Spinal Disord Tech 16:369-383, 2003

2. Ahn Y, Oh HK, Kim H, Lee SH, Lee HN: Percutaneous endoscopic lumbar foraminotomy: An advanced surgical technique and clinical outcomes. Neurosurgery 75:124-132, 2014

3. Bertagnoli R, Zigler J, Karg A, Voigt S: Complications and strategies for revision surgery in total disc replacement. Orthop Clin North Am 36:389-395, 2005

4. Brau SA, Delamarter RB, Schiffman ML, Williams LA, Watkins RG: Vascular injury during anterior lumbar surgery. Spine J 4: 409-412, 2004

5. Choi K-C, Lee DC, Shim H-K, Shin S-H, Park C-K: A Strategy of Percutaneous Endoscopic Lumbar Discectomy for Migrated Disc Herniation. World Neurosurg 99:259-266, 2017

6. David T: Revision of a Charité artificial disc 9.5 years in vivo to a new Charité artificial disc: Case report and explant analysis. Eur Spine J 14:507-511, 2005

7. Geisler FH: The CHARITE Artificial Disc: design history, FDA IDE study results, and surgical technique. Clin Neurosurg 53: 223-228, 2006

8. Kim $\mathrm{CH}$, Chung $\mathrm{CK}$ : Endoscopic interlaminar lumbar discectomy with splitting of the ligament flavum under visual control. J Spinal Disord Tech 25:210-217, 2012

9. Kim HS, Patel R, Paudel B, Jang J-S, Jang I-T, Oh S-H, et al: Early outcomes of endoscopic contralateral foraminal and lateral recess decompression via an interlaminar approach in patients with unilateral radiculopathy from unilateral foraminal stenosis. World Neurosurg 108:763-773, 2017

10. Komp M, Hahn P, Oezdemir S, Giannakopoulos A, Heikenfeld $\mathrm{R}$, Kasch R, et al: Bilateral spinal decompression of lumbar central stenosis with the full-endoscopic interlaminar versus microsurgical laminotomy technique: a prospective, randomized, controlled study. Pain Physician 18:61-70, 2015

11. Kostuik JP: Complications and surgical revision for failed disc arthroplasty. Spine J 4:289-291, 2004

12. Kurtz SM, van Ooij A, Ross R, de Waal Malefijt J, Peloza J, Ciccarelli L, et al: Polyethylene wear and rim fracture in total disc arthroplasty. Spine J 7:12-21, 2007

13. Leary SP, Regan JJ, Lanman TH, Wagner WH: Revision and Explantation Strategies Involving the CHARITÉ Lumbar Artifi- 
cial Disc Replacement. Spine (Phila Pa 1976) 32:1001-1011, 2007

14. Lee C-W, Yoon K-J, Ha S-S, Kang J-K: Foraminoplastic superior vertebral notch approach with reamers in percutaneous endoscopic lumbar discectomy: Technical note and clinical outcome in limited indications of percutaneous endoscopic lumbar discectomy. J Korean Neurosurg Soc 59:2016

15. McAfee PC, Geisler FH, Saiedy SS, Moore S V, Regan JJ, Guyer $\mathrm{RD}$, et al: Revisability of the CHARITE artificial disc replacement: analysis of 688 patients enrolled in the U.S. IDE study of the CHARITE Artificial Disc. Spine (Phila Pa 1976) 31:12171226, 2006

16. van Ooij A, Kurtz SM, Stessels F, Noten H, van Rhijn L: Polyethylene wear debris and long-term clinical failure of the Charité disc prosthesis. Spine (Phila Pa 1976) 32:223-229, 2007

17. Patel AA, Brodke DS, Pimenta L, Bono CM, Hilibrand AS, Harrop JS, et al: Revision strategies in lumbar total disc arth- roplasty. Spine (Phila Pa 1976) 33:1276-1283, 2008

18. Punt IM, Cleutjens JPM, de Bruin T, Willems PC, Kurtz SM, van Rhijn LW, et al: Periprosthetic tissue reactions observed at revision of total intervertebral disc arthroplasty. Biomaterials 30:2079-2084, 2009

19. Siepe CJ, Mayer HM, Wiechert K, Korge A: Clinical Results of Total Lumbar Disc Replacement With ProDisc II Three-Year Results for Different Indications. Spine (Phila Pa 1976) 31:19231932, 2006

20. Stieber JR, Donald GD: Early Failure of Lumbar Disc Replacement. J Spinal Disord Tech 19:55-60, 2006

21. Wagner WH, Regan JJ, Leary SP, Lanman TH, Johnson JP, Rao RK, et al: Access strategies for revision or explantation of the Charité lumbar artificial disc replacement. J Vasc Surg 44:12661272, 2006 